\title{
Tourism Infrastructure Construction Mode Optimization and Correlation Analysis of Related Industry Development
}

\author{
Ting Zhao \\ Qinghai University School of Finance and Economics, Xining City, Qinghai Province 810016, China.
}

\begin{abstract}
This research theoretically analyzes tourism infrastructure construction mode optimization and correlation analysis of general related industry development. With development of the tourism resources to the development of breadth and depth, the study of landscape protection and landscape planning gradually attention by people as many landscape planner, geographers, Lin, tourism experts and psychologists to landscape ecology, landscape and visual landscape perception, and get a lot of the methods and the techniques. So-called tourism policy is to promote national or the local tourism development of formulating and implementing relevant policies. This paper proposes the related and enhanced perspective on the infrastructure construction mode that is meaningful.
\end{abstract}

Keywords: Infrastructure construction; mode optimization; industry development; correlation.

\section{Introduction}

Construction of comprehensive reform pilot area, while the tourism is an effective path of reform and development of tourism, one of its core mission is to explore and advance boldly try to satisfy the needs of the tourism development tourism policy. So-called tourism policy is to promote national or local tourism development of formulating and implementing relevant policies, laws and regulations, rules and regulations, and the solution measures combined. Tourism policy is not only a country or the region important measures and means to promote the development of tourism and tourism industry is also a country or region management important basis and standards [1-2].

In general, the tourism public service system construction including the public transport services, tourism, public information service, tourism, public security, public service environment of tourism, tourist public assistance service and so on the five big aspects. (1) Tourism public security services include health and epidemic prevention of tourism, tourist food hygiene safety general public order maintenance of tourism, tourist safety fire safety and the special tourism program. (2) Tourism public assistance service mainly includes security assistance of tourism, tourist service quality assistance and travel assistance, etc. (3) Tourism public information service that mainly includes the tourist traffic indication system, tourist information indicator system, basic tourist information consultation system, tourist information public readings and travel sites such as the tourism information release and query system. (4) Tourism public environmental service mainly includes the monitoring of environmental health management tourist area environmental quality services and tourism public toilet construction.

Wisdom city development for tourism development laid a solid foundation, the development of the city not only focused on the wisdom of tourism, in medical wisdom, intelligent traffic, etc. all have involved. Major tourist cities in China focus on the development of intelligent application aspects of the tourism, including tourism resources, wisdom tourism services, tourism and wisdom of tourism marketing as wisdom tourist source refers to realize information exchange in the whole city, grasps the latest travel news dynamic. Under this basis, in the later sections, we will conduct research on the tourism infrastructure construction mode optimization and the correlation analysis of related industry development in detail with empirical analysis and corresponding discussion.

\section{Our Proposed Methodology}

\subsection{The Tourism Industry.}

Tourism industry is a comprehensive strong, high correlation, long industrial chain, especially the characteristics of the industrial convergence. Tourism is defined according to the needs of tourists, 
the tourists in the tourism process food, living, transportation, tour, entertainment, shopping consumption makes tourism can be naturally associated with various industries, almost any national economy industry association, to merge and it can create a series of new requirements, new markets, new products, new technology and new services, create a rich vitality of tourism new forms, and on the basis of traditional tourism forms through industrial development, evolution, integration and innovation. Cultural industry and the tourism industry cooperation, and that we have to break the boundaries, to realize the depth of the fusion culture and tourism, and go to cultural revitalization of the tourism, with tourism to carry forward the culture of roads to build up the common development of tourism and cultural platform. Enrich tourism with culture connotation, leading the direction of tourism development, improve tourism cultural taste, improves tourist creativity and competitiveness to promote the further better development of tourism [3-4].

In tourism, for the carrier of culture, to provide platform to show the culture, and culture, promote cultural innovation, and implementation of the development of cultural industry to expand the market space, to raise the transformation rate of cultural resources of commodities to realize the value of the culture as the product of combination of culture and tourism, and finally form a relate tourist cultural products. In the following Fig. 1, we demonstrate the basic architecture of the tourism industry.

Tapestry Tourism Structure Model Overview

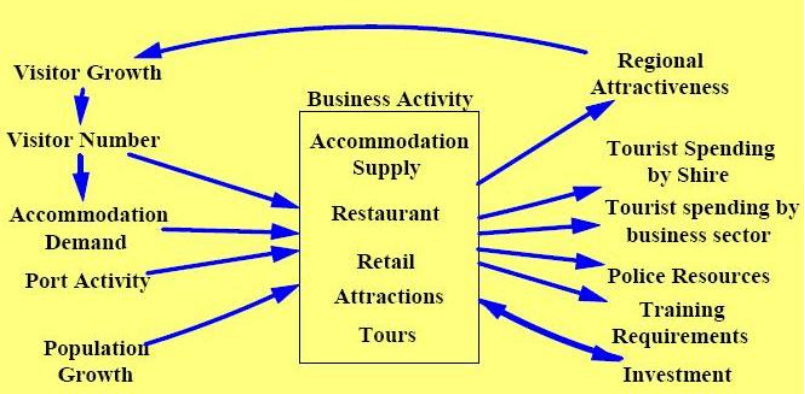

Fig. 1 The Systematic Architecture of the Tourism Industry

Among the basic forms of the tourism industry, the core features could be summarized as follows. (1) Wisdom of tourism is the advanced stage of the tourism industry informationization the traditional tourism industry value chain under information technology application in new generation weakened, new industry value chain, through new network integration of information technology to traditional enterprises to upgrade technology, fine division of labor, strengthen management as enterprises have also been restructuring in the position in the value chain. (2) In wisdom, in development of tourism industry based on Internet of things, cloud computing, big data of a new generation of the information technology industry has played a crucial role, to provide the information technology development and system integration of the enterprise, in an important position in the value chain. (3) In optimizing the wisdom of the tourism industry value chain, the tourism industry and information technology industry promote each other, basic coordinated development, innovation, complete value transfer, transfer and value-added to improve the added value of the whole industry and competitiveness.

\subsection{Tourism Infrastructure Construction.}

Industry is composed of the many attributes of the same enterprise. Thus the industry competitiveness is manifested by the competitiveness of the enterprises within the industry and the competitiveness of the enterprises is through the enterprise products or the general services provided by the competitiveness.

Tourism infrastructure belongs to the infrastructure of marketability, such as infrastructure, from the point of view of the economic properties of the products, with strong private interest feature can charge and can be competitive, these economic attribute determines such infrastructure in the supply of "marketability" characteristics, namely its supply activities can be placed on the market activity areas, according to market profit purposes, through market means. Therefore, tourism infrastructure and the market has a natural affinity, non-public capital should become the main form of the such infrastructure supply while the current financing through the following way, thus speeding up the construction of tourism infrastructure, to further promote healthy and rapid development of tourism 
in our country. Through this kind of cooperation form, all parties can achieve better results compared with expected to act alone. All parties involved in a project, the government is not the responsibility of project transferred to private companies, but by the parties to cooperate to share responsibility and financing risk. This model is one of the core most remarkable characteristics of the project is located government or affiliation with the project of the mutual coordination between investors and managers and their role in the project construction to reduce the investment risk.

Tourism facilities and travel services constitute the buying process of whole tourism products the competitiveness of the tourism industry that will show the whole tourism product competition ability. Therefore, tourism facilities and travel services are also part of the production elements in tourism is a necessary condition for core competence into real competitiveness. Divided tourist area to under the national unified planning. Make full use of favorable conditions of developing tourism in various areas. To improve the quality of tourism and other sectors of the economy coordinated development. Reasonable exploitation and utilization of tourism resources outstanding characteristics as give a full play to the superiority of the tourism industry to do this, to properly handle the core national unified tourism plan and adjust measures to local conditions of giving full play to the advantages of regional relations. It becomes one of the important principles guiding tourism division under the guidance of the principle of a chess game in the whole country. Each region should combine tourism with point based on the principle of system as a whole effect into play as reasonably determines the development direction of the regional tourism [5].

\subsection{Correlation Analysis of Related Industry Development.}

Regional harmonious development has become a hot issue in academic, its core lies in the different parts of the general industrial division and cooperation according to their respective advantages to support development of selective advantage industry, avoid the convergence of industrial structure achieve complementary and mutual benefit on the whole. Relevant scholars through the theory of regional gravity model meaning and limitations of the study, found that regional gravity is a specialized production the theory premise of existence, the area between the trade size is determined by the industry specialization degree, the higher the degree of specialization, the bigger deals. The study of industrial division of labor and the linkage has been relatively mature the study of regional industrial linkage is more, less research on the cross-regional industrial linkage, especially from the perspective of basic specific industries, China cross linkage of regional industrial division and comprehensive quantitative research is still in the stage of weak. Due to the regional economic development of our country and the differences of the resources endowment, determine the different areas of comparative advantage, which determines the industrial linkage path of different spatial directivity of each industry, is gradually by the enterprise of the regional division of labor and cooperation between the freedom of association between to industry chain, strategic alliance such as industrial cluster and the connection between the new form of industrial organization.

- Culture industry to promote the sustainable development of the core tourism industry. From the point of the tourism industry development model, tourism development has entered into the phase of mass tourism in China, a lot of scenic spots and tourist destination due to social, economic and environmental negative effects of the travel times of fatigue.

- The cultural industry promoted the optimization and upgrading of the tourism industry. From the consumption structure level, when people solve necessity of general basic consumption, leisure time increasing, then to make transition to enjoyment and development consumption and cultural consumer demand increase, the material product content increasing.

- Merger of culture industry, through its permeability and radiation, packed in culture support tourism, tourist guide and tourist. Tourism industry not only has higher cultural creative value and greater profit space, but also for the tourists to create a steady stream of cultural trends and fashion products, greatly improve the industrial function, further promote the tourism industry structure optimization and general corresponding upgrading.

Research under the condition of market economy operation law of industrial linkage, which is the key problem of seeking solid micro foundation for the industrial linkage theory, operation mechanism 
of analytical science to explain reasonably come to the system, the future research is necessary to take the network simulation, empirical and case method, analysis of macroscopic linkage phenomenon of microscopic mechanism that construct the core regulatory mechanism of joint network, optimize the interregional industry will be guide the rational flow of factors across regions, thus forming a logical since the general and corresponding economic based system.

\subsection{The Tourism Construction.}

Tourism is tourism product line of one point and it is the focus of tourism products and in the face of many tourism projects we how to perform under the principle of sustainable development, such as development and implementation of the project, progress in order to improve the quality of the tourism construction project implementation, it is necessary to introduce the concept of project management.

Tourism culture marketing refers to the use of basic tourism resources, tourism operators through cultural concept of design created to enhance the added value of the tourism products and services, to meet consumer demand for the good culture, and create tourism market exchange a way of marketing. Under this basis, we propose listed suggestions. (1) In the tourism construction project management, it is important to pay special attention to evaluate the project and work. Before the implementation of the project evaluation in the first place, namely completes the project feasibility report as also is the competent department of tourism research and analyze through the investigation and analysis on the report, to evaluate the feasibility and necessity of basic tourism projects. (2) To macro considerations, construction of the tourism projects, to guarantee the sustainable development of tourism projects, it's need to increase the ability of the government leadership and supervision, more dash forward show as tourist industry status and role of competent department of tourism administration. (3) Information management of construction project can be the introduction of the construction engineering project management system, its core is the three goals of project development better management, also is the process of construction project progress to set up personalized needs of project management system.

\section{Conclusion}

In this paper, we conduct research on the tourism infrastructure construction mode optimization and correlation analysis of the related industry development. After China's accession to the WTO, China's tourism industry will gradually to fully open, participate in international competition in the market. In the intensified competition, the competition range from local to expand to the whole new forms, new environment, the comprehensive promotion of the competitiveness of the tourism industry in China is to realize the tourism industry with the international community and the only way for world tourism power. Competitive advantage in the efficiency of industrial organization, and the cultural power and industrial policy under the influence of factors such as joint formed. Under this general basis, we later propose the novel perspectives on the optimization mode that is meaningful.

\section{References}

[1] Cvelbar, Ljubica Knežević, et al. "Drivers of Destination Competitiveness in Tourism A Global Investigation." Journal of Travel Research (2015): 0047287515617299.

[2] Wang, Donghong, et al. "The study on tourist destination tourism image perception and evaluation in Xi'an City." Agricultural Science \& Technology 14.9 (2013): 1285.

[3] Adebayo, Anthony K., and Anthony CO Iweka. "Optimizing the Sustainability of Tourism Infrastructure in Nigeria through Design for Deconstruction Framework."

[4] Vanhove, Norbert. "Tourism Projects and Cost-benefit Analysis." Handbook of Tourism Economics: Analysis, New Applications and Case Studies. 2013. 393-415.

[5] Alves, Simone, and Antônio Roberto Ramos Nogueira. "Towards a sustainable tourism competitiveness measurement model for municipalities: Brazilian empirical evidence." PASOS. Revista de Turismo y Patrimonio Cultural 13.6 (2015). 